\title{
Fan Ties and Friendships: A Longitudinal Network Study of Division III Sports on Campus
}

\author{
Matthew Katz, Ovidiu C. Cocieru², Daniel L. Springer ${ }^{3}$, \\ and Marlene A. Dixon ${ }^{3}$ \\ ${ }^{1}$ University of Massachusetts, ${ }^{2}$ University of Scranton, and ${ }^{3}$ Texas A\&M \\ University
}

\begin{abstract}
The purpose of this longitudinal actor-based network study is to examine the evolution of sport fan ties and friendship ties on Division III campuses. Using two years of network data from a cohort of new students at a Division III institution, a Simulation Investigation for Empirical Networks Analysis (SIENA) model is developed to empirically test the co-evolution of fan ties and friendship ties. Grounded in student development, sport consumer behavior, and network theories, the overarching goal of this study is to explore the causal effect of fan ties on friendship ties among new students. To ascertain the value of Division III sports on campus, the authors explore the role of sports on campus in promoting friendships for new students based on the strong theoretical tradition from student development highlighting the salience of peer relationships in student success and retention. Accordingly, theoretical implications related to sport fan networks are considered within practical discussion of Division III sports and retention.
\end{abstract}

Keywords: social network analysis, Division III athletics, longitudinal methods

Nearly $20 \%$ of students who enroll at higher education institutions (HEI) will not matriculate past their first year (McFarland et al., 2018). Raisman (2013) reported the average college loses just under $\$ 10$ million due to student attrition, with publicly assisted colleges ( $\$ 13.2$ million) averaging greater losses than private colleges and universities (\$8.3 million). Given that many colleges and universities are subsidized, at least to some extent, by the state or federal level, student retention and attrition are not merely issues for individual students. Schneider (2010), for example, estimated that state governments appropriated over $\$ 6$ billion to college and university students who did not persist to their second year. Improving retention, therefore, is not only a matter of sustainability for colleges and universities, but also of public service to ensure financial stewardship on the part of HEIs.

In examining student attrition, both academic researchers and practitioner organizations have emphasized the role of peer relationships in persistence decisions. Astin (1999) asserted that a "student's peer group is the single most important influ- 
ence of growth and development during the undergraduate years" (p. 398). InsideTrack (2018), an organization that works to reconnect college dropouts with HEIs, reported that $35 \%$ of traditionally aged students left college due to a lack of social community compared to the $11 \%$ who cited academics as the reason for departure. When Pascarella and Terenzini (2005) reviewed a decade's worth of research on educational attainment and persistence, they concluded that "peer influence is a statistically significant positive fore in students" persistence decisions" (p. 418). Though scholars have identified myriad other reasons for why students decide to leave higher education (Tinto, 2006), a student's ability to develop lasting and meaningful relationships with peers represents one of the most salient reasons they persist (Astin, 1999; Maunder, 2018; Swenson, Nordstrom, \& Heister, 2008).

Based on the importance of peer relationships, mechanisms for promoting friendships among new students become part of an organizational strategy to enhance student retention and educational success. Sport management scholars have consistently noted the intersection between peer relationships and sport spectating (Katz \& Heere, 2013; Lock \& Funk, 2016). Consuming sport as a fan or spectator may provide opportunities for salubrious socialization and the development of relationships (Chalip. 2006). Similarly, sport fans report increased social support through sport spectatorship that affects the emotional well-being of attendees (Inoue, Sato, Filo, Du, \& Funk, 2017). In other words, sport as a spectator activity might serve as a mechanism for promoting the types of relationships between students important to attainment and retention. Yet, there is no guarantee that sport will yield positive social results given that these outcomes are a function of how the sporting context is designed by sport managers and experienced by individual fans (Chalip, 2006; Guttman, 1986).

In the current study, we contribute to the literature by examining the causal effect of fan ties on friendships at the Division III level. Scholars have long examined the association between sports on campus and student outcomes. Yet a gap exists as to whether relationships formed through sport spectatorship on campus causes friendships among students. By using a longitudinal network approach, we examine causality on whether relationships embedded in Division III sport spectatorship lead to sustained friendships for students. Theoretically, we leverage student development, sport consumer behavior, and network theories to examine if Division III sports provide a context in which students create lasting and meaningful friendships through spectatorship. Division III sports is a particular sporting context that is largely void of commercial attention and direct revenue generation; yet such a sporting structure might create institutional value by building and maintaining peer relationships among new students. Using a longitudinal actor-based network study of new students at a Division III institution, the purpose of this study is to examine the evolution of sport fan ties and friendship ties for students on a Division III campus. Using two years of network data from a cohort of new students, we explore the causal effect of fan ties on friendship ties among new students to examine if and how Division III sports provide a context in which students create lasting and meaningful friendships through sport spectatorship. 


\section{Theoretical Frameworks}

\section{Student Development: Social Integration}

The study of how new students adapt to their college environment has largely been framed within Tinto's (1975) landmark theory of departure. Tinto (1993) distinguished between formal and informal integration into the campus community, noting that both academic and social integration lead to greater likelihood of persistence for students. Extending this concept, Astin's (1999) theory of involvement connects student success to the human interaction, collaboration, and interpersonal connections between students and other members of the campus community (e.g., peers, faculty, staff). In both of these prominent theories, the emphasis is largely placed on the relationships that students form during their transition into the campus community. Theoretically, as students become more integrated in the classroom and involved with various activities or organizations on campus they connect with individuals in the campus community and increase the likelihood of both success and persistencea notion that has received mixed support from a multitude of empirical studies (e.g., Pascarella \& Terenzini, 2005; Webber, Krylow, \& Zhang, 2014).

In addition to integration (Tinto, 1993) and involvement (Astin, 1999), scholars in student development have more recently adopted sense of belonging and attachment as theoretical frameworks related to student success (Strayhorn, 2012). Research in both attachment and sense of belonging shows that students' early experiences are influential throughout their time on campus. Strayhorn (2012) reported that early contacts impact sense of belonging to a larger degree if they involve relationships with peers whose background differs from one's own. Johnson et al. (2007), for instance, found smooth social transitions from high school to college significantly predicted feelings of belonging on campus. In their study, residence halls played an important role in forming early relationships. Likewise, Swenson and colleagues (2008) found that the type and quality of peer relationships students form impacted their academic, social, and emotional adjustment and led to greater levels of attachment to the institution. In addition, Maunder's (2018) findings showed that students who formed stronger relationships with their peers had stronger attachments to their institutions and were more likely to successfully adjust to college life.

For the purposes of this study, the underlying consensus from the works of Astin (1999), Tinto (1993), and Strayhorn (2012) is that relationships matter in understanding success in college, and that early experiences in the transition to campus are especially influential in determining the quality and type of relationships, and in forming attachment, involvement, and belonging for students that will impact the rest of their college career. Based on the conclusion that peer relationships enhance success for both student and organization, the next section of this article discusses network theory as a framework through which to examine student relationships on campus.

\section{Network Theory: Student Relationships as Network Ties}

The relationship between two individuals does not exist in isolation; individual actors are embedded in larger social systems comprised of individual actors and the ties 
connecting them (Borgatti, Everett, \& Johnson, 2013). Studying such social systems requires specific theoretical and methodological considerations - social network analysis. As Borgatti and Halgin (2011) noted, academic inquiries involving social network analysis have grown exponentially in recent years. In fields including health (Valente, 2010), leadership (Balkundi \& Kilduff, 2006), management (Brass, Labianca, Mehra, Halgin, \& Borgatti, 2014), and sport management (Quatman \& Chelladurai 2008), relationships and their associated patterns continue to predict and explain a wide array of individual- and group-level outcomes. Grounded in the assumption that both relationships and structure matter, the network approach provides a framework for incorporating and appreciating the interdependencies of social behavior (Prell, 2012). Network theory, according to Borgatti and Halgin (2011), involves the consequences of network variables and the ways in which network properties relate to some predefined outcome of interest.

Several scholars have examined social integration through network approaches. McEwan (2013), for example, emphasized how social integration involved more than individual relationships, illustrating the benefits of studying retention through a network lens. Through a network study of new students at a larger southwestern university, McEwan (2013) found that a new student's satisfaction with their social networks was related to institutional commitment. It was not merely the number of ties a student had, but satisfaction with the larger network of ties suggesting the importance of networks in persistence. Similarly, Thomas (2000) emphasized the need for examining Tinto's (1993) social integration through a network approach. In a study of freshman at a small liberal arts college, Thomas (2000) found that structural characteristics of a student's social network influence both academic performance and persistence intentions. Rather than examining student relationships as isolated relationships, McEwan (2013) and Thomas (2000) illustrated the importance of incorporating network theories and methodologies to study peer relationships and persistence behavior.

Whereas traditional social science research methods predict some individual outcomes based on other characteristics of the individual, the network approach utilizes the individual's social environment in addition to other individual characteristics to explain and predict outcome variables (Borgatti \& Foster, 2003). Such relational characteristics need to be included because one's position in a network, in part, determines many of the constraints and opportunities an individual will encounter (Borgatti et al., 2013). As Marin and Wellman (2014) argued, individual behaviors and attitudes generally are not located only in individual attributes, but in the social structure within which individuals are embedded. Understanding relationships between two actors requires such a network approach. The relationship in a network is conceptualized as a tie, and it is the tie that gives rise to a corresponding network (Borgatti et al., 2013). Actors are simultaneously embedded in a variety of networks (i.e., friendships, colleagues, family members), and these different networks may impact each other. A new student's friendship network, for example, could theoretically be affected and impacted by the evolution of a student's other relational networks including a sport fan network. 


\section{Sport Consumer Behavior: Fan Networks and Sports on Campus}

For new students on campus, intercollegiate athletics may play a prominent role in the development of interpersonal relationships. Sport scholars have consistently noted the prevalence of personal relationships in the initial socialization of sport fans (James, 2001). It is often interpersonal relationships that help new fans navigate the unique challenges of developing identification with a focal team (Lock, Taylor, Funk, \& Darcy, 2012). As new students begin their onboarding and socialization into campus culture, their emerging friendships are intrinsically linked with other burgeoning relational ties as well (i.e., roommate, classmate). Could watching sports together be similarly linked with the evolution of friendship ties? Sport scholars discuss the relations between individual fans, and how fan-to-fan interactions create valuable experiences for individuals (Uhrich, 2014). Rather than conceptualizing a crowd at a game as some monolithic entity, crowds of fans are more representative of an aggregation of individual actors interacting with other actors (Katz \& Heere, 2013). In other words, a crowd or fan base is a network of individual fans connected by varying ties and relations.

The notion of "sport fan communities" has garnered increased attention by sport management research (e.g., Asada \& Ko, 2019; Yoshida, Heere, \& Gordon, 2015). Within these communities, individual fans are influenced by both a psychological sense of community and individual relationships with other members (Katz, Ward, \& Heere, 2018). Specifically, on college campuses, sport scholars have studied how a student's psychological connection to a sports team affects their corresponding sentiments towards the university. Research by Wann and Robinson (2002), Clopton (2008), Clopton and Finch (2008), Warner, Shapiro, Dixon, Ridinger, and Harrison (2011), Heere and Katz (2014), Katz and Heere (2016), and Stensland, Taniyev, Scola, Ishaq, Wilkerson, and Gordon (2019) has together formed a somewhat cohesive narrative, finding moderate to strong evidence for the relationship between fandom and sentiment towards the institution of higher learning. Specifically, Katz and Clopton (2014) found that identification with Division III athletic teams contributed to students' increased identification with the surrounding community. Katz, Dixon, Heere, and Bass (2017) also examined the Division III setting, suggesting Division III athletics serve as a "front porch" for new students. More specifically, they found that growth trajectories of team identification significantly affected changes in university identification. In other words, how new students identified with the sports teams on campus had a causal effect on how students identified with the larger university.

As scholars show that psychologically connecting with sports on campus impacts sentiments towards the larger university, we might hypothesize that psychological connections impact persistence decisions as well. But a psychological connection is not equivalent to peer relationships. As scholars like Astin (1999), Tinto (1993), and Strayhorn (2012) have emphasized, peer relationships play the most important role in retention and persistence. Such peer relationships are the strongest and most consistently validated indicator of success and retention in college (Pascarella \& Terenzini, 2005). And though linking Division III sports on campus with 
other indicators of psychological attachment (e.g., university identity) is a great start to understanding the role of sport on theses campuses, the value of Division III sports is best examined through its effect on interpersonal relationships. We aim to address this gap; to test whether sport fan ties cause interpersonal relationships among new students. The capacity for sport at this level to provide a platform to foster and maintain peer relationships for general students (not just athletes) enhances the institutional value of sponsoring Division III athletics.

\section{The Evolution of Ties: Longitudinal Social Network Analysis}

Peer relationships are not static constructs; relationships are formed, maintained, and potentially dissolved during the course of a student's time on campus. Studying the impact of sport fan ties and peer relationships thus requires a longitudinal lens. Network scholars have developed a series of longitudinal network modeling methods to examine the evolution of networks, including stochastic actor oriented modeling (SAOM) techniques and yet these approaches are largely absent from sport management research. Social networks are inherently dynamic given that individuals create, endure, and potentially dissolve different ties over time (Snijders, van den Bunt, \& Steglich, 2010). Both individual ties and the resulting network structure can change substantially in both the short- and long-term, and network scholars have increasingly utilized actor-based longitudinal modeling to examine network evolution (Prell, 2012). In fact, to study network influence or the co-evolution or multiple ties, longitudinal methods are necessary to model how network change occurs (Borgatti et al., 2013).

To guide the present study, we specifically utilize SAOM to highlight the actor-based perspective whereby it is assumed that individual actors control their own actions. That is, each individual in a network is thought to evaluate their own relations with others and strive to optimize their own social situations (Prell, 2012). In this way, SAOMs assume that actors control their outgoing ties and have agency over to whom they send interpersonal ties (Snijders et al., 2010). For the case of friendships and sport fan ties, these underlying assumptions are satisfied as individual students control with whom they report being friends and attending sporting events. Moreover, SAOMs incorporate the changes individual actors make over time, examining the stochastic dependence between the creation, continuation, and potential termination of network ties (Snijders et al., 2010). Developing SAOM models involves identifying particular structural effects (i.e., transitivity), control variables (i.e., gender), and dyadic network effects to include in the models. In the following section, we outline the specific hypotheses appropriate for a SAOM approach to studying the evolution of sport fan ties and friendship ties on Division III campuses.

\section{Hypothesis Development: Structural Effects}

Within SAOMs, structural effects refer to endogenously determined effects, such as they are a function of current network characteristics (Snijders et al., 2010). The most basic structural effects involve centrality, one of the most prominent and popular constructs used in social network analysis. Centrality refers to a family of con- 
cepts that, in an aggregate sense, refer to the structural importance of each individual actor within a network (Borgatti et al., 2013). From the perspective of the individual node, centrality is conceptualized as the benefits and advantages an individual receives due specifically to their position in the network. In SAOMs, we must differentiate between indegree centrality and outdegree centrality. Indegree centrality is the number of ties received by an actor from others, whereas outdegree centrality is the number of ties given by an actor to others in the network (Borgatti et al., 2013; Prell, 2012). Outdegree centrality is the most basic effect and represents the tendency for individuals to have ties at all, described as the likelihood that actor $i$ sends ties to alter $j$, where $j$ has no specific structural or attributional characteristic that makes them more attractive. Our first hypothesis utilizes the outdegree effect for both the fan (H1a) and friendship (H1b) networks, both of which should yield negative estimates. Indegree centrality is viewed as a measure of popularity, where actor $i$ received more ties from others in the network than the average actor. Indegree centrality is often examined through popularity effects, whereby those actors with higher incoming ties are more likely to attract more incoming ties in future waves of data collection. A positive indegree popularity implies fans with high indegree reinforce themselves, which will yield a high dispersion of indegree ties among network members. Our second hypothesis (H2) utilizes the indegree-popularity effect for the fan network.

Beyond centrality, the next structural effect hypothesized involves reciprocity. Reciprocity represents an important network effect in directed networks, whereby actor $i$ is likely to return a tie with actor $j$, if actor $j$ sends a tie to actor $i$. Reciprocation is common in directed networks, because reciprocation and exchange are fundamental components to social behavior (Robins, 2015). In fact, Borgatti et al. (2013) suggested including reciprocity in all SAOMs because of inherent social tendencies towards reciprocal relationships. In understanding fan ties, reciprocity measures whether two individuals both report sharing a fan tie with the other. Intuitively, reciprocity should be inherent to fan ties because both individuals participate in attending the event or communicating about a particular team. Reported ties, however, are influenced by the perception of the actor; whether an individual remembers a tie or deems the experience as noteworthy enough to report illustrates the inherent value of the tie. In other words, there is no guarantee that actor $i$ and actor $j$ will both remember and report a sport fan tie, even if co-attendance or communication took place. The inclusion of reciprocity is designed to test the meaningfulness and importance of the fan tie to both actors in the exchange. Our third hypothesis utilizes the reciprocity effect for both fan ties (H3a) and friendship (H3b) ties.

The final set of structural effects include transitivity. Transitivity is an essential feature of most social networks, whereby friends of friends become friends (Borgatti et al., 2013; Snijders et al., 2010). Triads are often conceptualized as the building blocks of larger networks (Prell, 2012; Robins, 2015) and much can be learned about network structure by examining transitivity within the network. In the present study, we not only test for the existence of the transitivity effect but also how transitivity occurs by including effects for transitive triplets and three-cycles. Transitive triplets refer to situations where actor $i$ sends a tie to alter $j, j$ sends a tie to $h$, and thus $i$ will 
send a tie to $h$ and close the triad. The closed triad is highly dependent on a single node, $h$, as the single node receives two ties within the triad, and one node, $i$, receives no incoming ties, indicating the presence of hierarchical ordering (Robins, 2015; Snijders et al., 2010).

Hierarchical ordering in triads represents the influence of hubs at the local level, where even at the smallest levels of network structure actors depend on a subset of the population. A different way to interpret transitivity, the three cycle effects, refers to situations where each actor sends and receives exactly one tie; actor $i$ sends a tie to alter $j, j$ sends a tie to alter $h$, and consequently $h$ will send a tie back to $i$. Such a triad represents the absence of hierarchical cluster and the presence of closure through a more generalized exchange (Snijders et al., 2010). Three cycles can also be regarded as generalized reciprocity within triadic closures (Ripley, Snijders, Boda, Voros, \& Preciado, 2019). Our fourth hypothesis (H4) utilizes the transitive triplets effect for fan ties and the fifth hypothesis (H5) uses the three-cycle effect for fan ties, which should yield a negative estimate.

\section{Hypothesis Development: Covariate Effects}

The structural effects above are conceptualized as endogenously determined effects, such that they are a function of the network characteristics. Conversely, covariate effects (i.e., individual behaviors or attributes) are conceptualized exogenously in that they are a characteristic of the individual nodes. Within SAOMs, covariate effects can occur in three ways (Snijders et al., 2010). First, the ego effect measures whether a focal actor with some attribute tends to have higher outdegree measures. Second, the alter effect measures whether actors with some attribute receive higher indegree ties. And third, the similarity effect measures whether ties occur more often between actors who share similar values on the attribute of interest.

The similarity effect is grounded in homophily, one of the oldest and most frequently replicated findings in all of social psychology (Borgatti et al., 2013). It refers to the tendency for individuals to have positive ties to individuals who are similar to themselves in significant attributes or characteristics (Prell, 2012). In the present study, we utilize team identification as the characteristic of interest within the covariate effects. Team identification is perhaps the most widely studied construct in all of sport management (James, Delia, \& Wann, 2019), as scores of scholars have examined the relationship between an individual's team identification with consumption behaviors such as attendance and media consumption (Lock \& Heere, 2017). Consistent with Lock and Heere's (2017) analysis of team identification, we conceptualize team identification as the part of an individual's self-concept derived from their membership in a social group (sport team) with the value and emotional significance of belonging to such group, a definition consistent with Tajfel's (1982) operationalization of social identity. As the most prominent construct within sport marketing and sport consumer behavior, we hypothesize that alters with higher levels of team identification will attract more incoming ties in the fan network (H6a) and friend network (H6b); that individuals with higher levels of team identification will send more outgoing ties in the fan network $(\mathrm{H} 7 \mathrm{a})$ and friend network $(\mathrm{H} 7 \mathrm{~b})$; and 
that individuals send more ties to alters with similar team identification values in both the fan network (H8a) and friend network (H8b).

\section{Hypothesis Development: Dyadic Effects}

The final classification of effects involves dyadic effects, or between-network co-evolution. Our second stated purpose in this research is to examine the evolution of sport fan ties and friendship ties on Division III campuses. The co-evolution of two networks occurs through modeling the dyadic effects of fan ties with friendship ties. Given the longitudinal nature of the study, dyadic effects are able to approximate directionality and causality; topics that cross-sectional designs do not examine. To examine the effect of fan ties on friendship ties, we included two different dyadic effects. First, we included a Main Effect of fan ties on friendship ties, whereby actors $i$ and $j$ attending a sporting event together lead to a friendship tie. The Main Effect incorporates causality, examining whether a fan tie leads to the formation of a friendship tie, our ninth hypothesis (H9). Additionally, we also tested a dyadic effect regarding indegree popularity. Within dyadic effects, indegree popularity refers to situations whereby actors with high indegree in the first network, also attract more indegree ties in the second network. For the tenth (H10) and final hypothesis, we examine whether actors with high fan ties indegree will attract greater incoming friendship ties as a result. Again, the indegree popularity dyadic effect is an approximation of causality, whereby greater indegree ties in the fan network lead to greater indegree ties in the friendship networks.

\section{Method}

\section{Participants and Procedure}

The sample for this longitudinal actor-based network study consisted of a freshman orientation group at a small, private institution in the southwestern United States. To protect the anonymity of the research setting and participants, the specific Division III institution will be referred to as South College. South College has participated in Division III athletics for several decades and is largely representative of the 'typical' Division III institution. According to the NCAA (2018), the average Division III institution has 2,758 undergraduate students, sponsors 18 sports, spends $\$ 4.2$ million annually on athletics, and student athletes comprise $26 \%$ of the student body population. South College enrolls approximately 2,300 undergraduate students, sponsors 15 sports (including football), and reports an annual athletics budget of $\$ 4.3$ million. Additionally, student-athletes comprise about $25 \%$ of the student population. Based on these characteristics, South College was deemed an appropriate research setting largely indicative of the 'typical' Division III institution. It is also worth noting that South College considers itself academically selective and often finishes in the upper echelon of the Directors' Cup, an annual program recognizing broad-based athletic success based on team performances, indicative of a successful Division III athletics program in terms of performance. 
The specific students from South College invited to participate in this study were all members of a freshman orientation group. After initial discussions with administrators at South College, campus leaders recommended utilizing an orientation group as the sample population. This particular orientation group consisted of 15 new students who experienced the institution's orientation program together and were placed in the same dormitory during their first year on campus. The group was not formed on the basis of any shared characteristic - not a similar major, demographic characteristic, or extracurricular activity - as the university "randomly" created the orientation group. The sample group contained 15 new students who were all recruited to participate in the study during their first few weeks on campus. Two potential participants declined to participate, and as a result the study began with 13 members of the orientation group, representing $87 \%$ of the orientation group. The average age of the participants was 18 years old and each student was in their first semester on campus. A slight majority of the participants identified as female $(n=$ $8,61.5 \%$ ) which is largely representative of the broader university population as indicated by the campus leaders.

SAOMs require a minimum of two, but preferably more, repeated observations among actors of the same network (Snijders et al., 2010). To collect our network panel data, we designed a data collection procedure to take place over the course of four semesters; the first four semesters of our participants' tenure at South College. For four consecutive semesters, with two weeks remaining in the semester, participants received an email from the lead researcher with a direct link to an electronic survey. Each participant had previously agreed to participate in the study and was consequently aware of when, and from whom, the survey invitation would arrive. A second reminder was distributed to non-respondents approximately two days after the initial request. Because network studies demand high response rates, a small incentive (i.e., free pizza) was provided to ensure participants completed each round of the survey. All 13 participants completed the network questionnaire in each round of the study.

\section{Instrumentation}

The electronic survey for this study contained measures designed to capture both network ties and individual attributional data. For the network measures, we utilized a roster-based approach aimed at ensuring accuracy and recall (Prell, 2012). In a roster-based approach, participants are given a list of all members of the network population and asked to answer particular relational questions regarding that individual. Roster-based approaches are less susceptible to recall bias and are generally considered the most reliable form of data collection when a network boundary is easily identified (Borgatti et al., 2013). The roster remained the same across all four waves of data collection.

The Network Questionnaire. First, participants were asked to indicate whether they considered each name listed as a personal friend. There was no predetermined minimum or maximum number of friends each participant could select. Next, using 
the same roster, participants were asked to indicate whether they had attended a sport event on campus with each member of the network. The brief instruction explained the "fan tie" question involved any varsity sport sponsored by their university and included in-person attendance at the event. The minimum or maximum number of names was determined individually by each participant.

Team Identification. In addition to network questions, participants were asked to complete a modified version of Heere and James' (2007) Team*ID scale. The Team*ID scale is multidimensional and grounded in Social Identity Theory. Based on Lock and Heere's (2017) review of measuring team identification, the Team*ID scale is considered theoretically legitimate for our purposes and has been used many times in the study of college students as sport fans (Heere \& Katz, 2014; Katz et al., 2017). The Team*ID scale consists of six dimensions of social identity, with individual items measured with Seven-Point Likert Scales: 1) Private evaluation (e.g., I feel good about being a fan of South College athletics); 2) Public evaluation (e.g., In general, others respect South College athletics); 3) Interconnection of self (e.g., When someone criticizes South College athletics, it feels like a personal insult); 4) Sense of interdependence (e.g., What happens to South College athletics will influence what happens in my own life); 5) Behavioral involvement (e.g., I participate in activities supporting South College athletics); and 6) Cognitive awareness (e.g., I am aware of the tradition and history of South College athletics).

The Team*ID scale was distributed with the network questionnaire during each wave of data collection. While all participants completed the network questionnaire at each wave, we had a few instances of missing data in terms of team identification: one missing during the second wave; four missing during the third wave; and one missing during the fourth wave of data collection. Missing data is a common issue that researchers have to deal with (McKnight, McKnight, Sidani, \& Figueredo, 2007). The statistical technique that has received the most praise from scholars in handling missing data is Multiple Imputation (MI) (Allison, 2002; Rubin, 2004; Schafer \& Graham, 2002). Through multiple imputations, for each missing datum, three to 10 values are estimated and imputed based on the available data. For each set of imputed values, the researcher obtains a complete dataset. We performed the MI procedure five times on our dataset, which is an acceptable number of iterations (McKnight et al., 2007). We then averaged the five completed datasets to arrive at our final Team ID covariates.

\section{Data Analysis}

After four waves of data collection over the course of two academic years, our final data contained actor-based network data regarding fan ties, friendship ties, and team identification as a covariate at each wave. Using these data, we began developing the SAOMs. In order to examine the evolution of the fan ties network and the co-evolution of fan ties and friendship ties, we used the Simulation Investigation for Empirical Network Analysis (SIENA), a specific type of SAOM modeling technique. SIENA is a statistical approach that allows for the examination of longitudi- 
nal network data with two more observations. A defining feature of SIENA is the consideration of change in a network from the perspective of the actors, consistent with the actor-based approach. SIENA views change in a network as determined by a series of micro steps made by individual actors to create, maintain, or dissolve ties in a network. These micro steps are not observed by the researchers but are modeled by the algorithm in a series of network simulations. Researchers can use SIENA to define models with effects that they think influence the evolution of a network, and then test whether these effects are significant in impacting the dynamic evolution of the network (Snijders et al., 2010).

Using multiple waves of network panel data, SIENA views the network ties as the results of decisions made by each individual actor. SIENA is considered an actor-based approach because each actor controls their outgoing ties; each change in a network tie is thus conceptualized as the result of choices made by individual actors. To use SIENA, a dataset and modeling technique must meet four model assumptions (Snijders et al., 2010). First, the 'time' parameter must be continuous and unfold in steps of a certain length. Second, network changes are the outcome of Markov processes where, for each point in time, the current state of the network determines probabilistically later evolutions of the network. This assumption requires a meaningful independent variable to individual actors and incorporates any meaningful information from the past. Third, actors control, and have the ability to change, their own outgoing ties during subsequent waves of data. And finally, the fourth assumption of SIENA states that each actor gets the opportunity to change one outgoing tie at any moment without requiring coordination of other ties. As long as ties can change one by one, the fourth assumption is satisfied (Snijders et al., 2010). Based on our interpretation of these four assumptions, our dataset and analytical strategy align with SIENA, specifically the SIENA packing in R (RSIENA; Ripley, Snijders, Boda, Voros, \& Preciado, 2019).

SIENA models include two kinds of parameters: rate parameters and objective function parameters. Rate parameters refer to the tendency of individual actors to change their ties with others in the network. Objective function parameters measure the probability that a tie is created, maintained, or eliminated following a certain pattern. That is, objective functions test whether a particular network's structural tendency (i.e., transitivity), individual attributes or covariates (i.e., gender), or the impact of other networks through co-evolution (i.e., friendship and fan ties) significantly affect the probability of tie creation, maintenance, or elimination. Objective functions are tested using t-statistics, defined as the estimate divided by the standard error.

For our particular SIENA model, we included several parameters with corresponding explanations and graphical representations included in Table 1. To examine the evolution of the fan ties networks, outdegree (density) and reciprocity were first included followed by indegree popularity, transitive triplets, and three cycle objective functions. As covariates in the fan tie network, team identification was included at each level of potential covariate effect: ego, alter, and similarity. In addition to the fan ties model, we also utilized SIENA's ability to test multiplex network parame- 
Table 1

Explanation of Model Effects

\begin{tabular}{|c|c|}
\hline Effect used & Description \\
\hline \multicolumn{2}{|l|}{ Structural effects } \\
\hline Outdegree (density) & Actor $i$ sends ties to alter $j$. \\
\hline Reciprocity & Actor $\mathrm{i}$ reciprocates ties with alter $\mathrm{j}$. \\
\hline Transitive triplets & $\begin{array}{l}\text { Actor } i \text { sends ties to alter } j, j \text { sends ties to } h \text {, } \\
\text { so } i \text { is likely to send ties to } h \text {. }\end{array}$ \\
\hline Three cycles & $\begin{array}{l}\text { Actor } i \text { sends ties to alter } j, j \text { sends ties to } h \text {, } \\
\text { so } h \text { is likely to send ties to } i \text {. }\end{array}$ \\
\hline Indegree-popularity & $\begin{array}{l}\text { Actors with many incoming ties attract more } \\
\text { incoming ties. }\end{array}$ \\
\hline \multicolumn{2}{|l|}{ Covariate (Team ID) effects } \\
\hline Team ID alter & $\begin{array}{l}\text { Actor } i \text { with higher values of Team ID at- } \\
\text { tracts more incoming ties. }\end{array}$ \\
\hline Team ID ego & $\begin{array}{l}\text { Actor } i \text { with higher values of Team ID sends } \\
\text { more outgoing ties. }\end{array}$ \\
\hline Team ID similarity & $\begin{array}{l}\text { Actor } i \text { sends ties to alter } j \text { who has similar } \\
\text { values of Team ID. }\end{array}$ \\
\hline \multicolumn{2}{|l|}{ Between-network dyadic effects } \\
\hline $\begin{array}{l}\text { Main effect of Sport Fan Tie } \\
\text { network on Friendship network }\end{array}$ & $\begin{array}{l}\text { For actors } i \text { and } j \text {, attending sporting events } \\
\text { together on campus leads to relationship or } \\
\text { friendship. }\end{array}$ \\
\hline $\begin{array}{l}\text { Sport Fan Tie indegree } \\
\text { on Friendship popularity }\end{array}$ & $\begin{array}{l}\text { Actors that attend sporting events with many } \\
\text { alters, also attract more friendship ties. }\end{array}$ \\
\hline
\end{tabular}

ters, or the effects of relations in one network on relationships in another network (Snijders, Lomi, \& Torlo, 2013). To examine the co-evolution of friendship ties, we first included both outdegree (density) and reciprocity for friendship ties, which are both included by default in RSIENA functions. We also tested team identification at each level of potential covariate effect within the friendship network. Finally, to examine whether fan ties create friendships among new students, we included a 'Main Effect' parameter for the effect of a fan tie on friendship ties. We also tested whether popularity in the sport ties network leads to popularity in the friendship network as a secondary measure of the effect of fan ties on friendship ties.

\section{Results}

The SIENA models created in this study were designed to explore the evolution of sport fan networks and examine how fan ties affect friendship ties for new students at a Division III institution. Full results of the models can be found in Table 2, which includes rate parameters, structural effects, covariate effects, and co-evolution 
effects for both fan ties network and friendship network. The overall model reported a convergence ratio of 0.1917 , which suggests the RSIENA algorithm converged appropriately as it falls below the 0.25 threshold suggested by Ripley et al. (2009) as an indicator of fit. The rate parameters for the fan ties networks indicates that fan tie evolution peaked during the first time period, and largely slowed during the final wave. The rate parameters for the friendship networks were much smaller and more constant, suggesting more consistent changes to friendships than fan ties. It is worth noting here that rate parameters are not significant, which is consistent with RSIENA expectations as a significant result would suggest they are equal to zero (Borgatti et al., 2013).

Based on the structural effects for the sport fan network, the SIENA model yielded significant results for outdegree (density), reciprocity, transitive triplets, and three-cycles; indegree-popularity was non-significant. In terms of our stated hypotheses, we found support for H1a, a basic tendency for individuals to send ties at all. The negative estimate indicates that actors are not likely to send fan ties to an arbitrary actor without any attractive structural and attributional characteristics. Because indegree-popularity reported a non-significant effect, $\mathrm{H} 2$ was not supported. H3a was supported through a positive and significant effect of reciprocity, suggesting shared fan ties were reported by both actors. Examining the transitivity results, the significant positive estimate for transitive triples combined with a negative significant effect for three-cycles strongly supports $\mathrm{H} 4$ - the presence of a transitivity with hierarchical closure. Accordingly, H5 was not supported based on the negative effect of three-cycles. The covariate effects based on team identification were not significant at the ego, alter, or similarity levels, providing no support for H6a, H7a, and H8a.

Moving to the friendship network, both outdegree (density) and reciprocity were statistically significant. Outdegree was negative, suggesting that friendships with arbitrary network members were more likely not to occur, supporting H1b. Reciprocity was positive, indicating friendships followed basic tendency of reciprocal relationships and supporting $\mathrm{H} 3 \mathrm{~b}$. The covariate effects of team identification were not significant at the ego, alter, or similarity level, providing no support for H6b, $\mathrm{H} 7 \mathrm{~b}$, and $\mathrm{H} 8 \mathrm{~b}$.

Finally, examining the dyadic network effects of fan ties on friendship ties, the main effect was not significant while the indegree popularity effect was significant. The non-significant estimate for the main effect rejects $\mathrm{H}$, finding no statistical support for fan ties leading to friendship ties. To reiterate, a non-significant main effect suggests that two actors attending a game together does not necessarily lead to a friendship tie developing. The indegree popularity effect, however, was positive and significant, supporting H10. Actors with high fan tie indegree do attract greater incoming friendship ties; indegree popularity in the fan network leads to indegree popularity in the friendship network. 
Table 2

Results of SIENA Model

\begin{tabular}{lcccc}
\hline Hypothesis & Estimate & $\begin{array}{c}\text { Standard } \\
\text { Error }\end{array}$ & $\begin{array}{c}\text { Convergence } \\
\text { t-ratio }\end{array}$ & Sign. \\
\hline
\end{tabular}

Rate parameters (Sport Fan Ties network)

$\begin{array}{llrrr}--- & \text { Rate parameter period 1 } & 12.5852 & 11.1558 & -0.02 \\ --- & \text { Rate parameter period 2 } & 8.0772 & 3.656 & -0.0782 \\ --- & \text { Rate parameter period 3 } & 3.3361 & 1.0278 & -0.0827\end{array}$

Structural effects (Sport Fan Ties network)

$\begin{aligned} \text { H1a } & \text { Outdegree (density) } \\ \text { H2 } & \text { Indegree - popularity } \\ \text { H3a } & \text { Reciprocity } \\ \text { H4 } & \text { Transitive triplets } \\ \text { H5 } & \text { Three-cycles }\end{aligned}$

Covariate Effects (Sport Fan Ties network)

$\begin{array}{lllll}\text { H6a } & \text { Team ID alter } & 0.1199 & 0.1292 & 0.0145 \\ \text { H7a } & \text { Team ID ego } & 0.1266 & 0.1391 & 0.0009 \\ \text { H8a } & \text { Team ID similarity } & 0.3018 & 0.4796 & 0.0256\end{array}$

Rate parameters (Friendship network)

$\begin{array}{llrrr}--- & \text { Rate parameter period 1 } & 3.8924 & 1.0448 & -0.0616 \\ --- & \text { Rate parameter period 2 } & 4.9664 & 1.4687 & -0.0115 \\ --- & \text { Rate parameter period 3 } & 4.2353 & 1.296 & 0.0429\end{array}$

Structural effects (Friendship network)

\begin{tabular}{|c|c|c|c|}
\hline H1b Outdegree (density) & -1.5776 & 0.2623 & 0.0422 \\
\hline Reciprocity & 2.1969 & 0.3634 & 0.0513 \\
\hline
\end{tabular}

Covariate Effects (Friendship network)

$\begin{array}{llrrr}\text { H6b } & \text { Team ID alter } & -0.1612 & 0.1535 & -0.0158 \\ \text { H7b } & \text { Team ID ego } & -0.0066 & 0.143 & -0.0045 \\ \text { H8b } & \text { Team ID similarity } & 0.8295 & 0.4981 & -0.0145\end{array}$

Dyadic network effects (Sport Fan Ties network effect on the Friendship network)

$\begin{array}{rlrrr}\text { H9 } & \begin{array}{l}\text { Main effect of Sport } \\ \text { Consumption network on } \\ \text { Friendship network } \\ \text { Sport Consumption } \\ \text { popularity effect on }\end{array} & 0.8161 & 0.7295 & 0.091 \\ \text { Friendship popularity } & 0.7511 & 0.3783 & 0.0345 & *\end{array}$

Overall maximum convergence ratio: 0.1917

${ }^{*} p<0.05$

** $p<0.01$ 


\section{Discussion}

Our purpose for this research was to explore the evolution of sport fan networks and examine how fan ties affect friendship ties among new students at a Division III institution. In examining the fan and friendship network, we aimed to contribute to both the sport consumer behavior and student development literatures by highlighting the relationship between fan ties and friendships. Grounded in the importance of social integration (Tinto, 1993) and peer relationships (Astin, 1999) with respect to persistence and retention, we begin our discussion of the SIENA model results of the dyadic effects examining the co-evolution of fan and friendship ties. The non-significant dyadic network effects of fan ties on friendships ties indicates that attending games together does not necessarily lead to the formation of friendships. In other words, attending games together did not cause friendship to form. Such a finding is somewhat divergent from previous research using psychological measures as proxies for social integration (i.e., Clopton, 2008; Katz et al., 2018), which consistently link measures of sport consumption (i.e., team identity) with proxy measures for social integration (i.e., university identity). The development of fan ties did not significantly affect the formation of relationships for the new students in this study. Only one participant in the study reported never attending a game with someone else in the group, yet these co-attendance events did not significantly affect friendship ties.

Though fan ties might not cause friendship ties, the significance of the indegree popularity effects suggests fan ties and social integration are related. As individual actors receive more incoming ties in the fan network they are more likely to then receive incoming ties in the friendship network. These ties might not come from the same actor. If the same actor sending a fan tie caused a friendship tie, the dyadic network effect would have been significant. Based on this finding, however, incoming ties in the fan network seem to cause other actors to send friendship ties moving forward. Thomas (2000) and McEwan (2013) both linked new students finding peer relationships to persistence decisions. The indegree popularity effect provides support for sport spectatorship yielding incoming friendship ties. Attending sporting events on campus together might not cause friendships with the same actor, but popularity in the fan networks signals to others the value of one's role in the friendship network as well. Peer relationships are particularly important for new students early in their transition to campus (Strom \& Savage, 2014); for the participants in this study, attending sporting events together led to receiving more friendship ties moving forward and, consequently, greater social integration.

Receiving sport fan ties appears to be a successful strategy for positioning oneself to receive future friendships.

Though the indegree popularity effect was significant between the fan and friend networks, the fan network itself was not marked by an indegree popularity effect. Becoming more popular within the fan network did not lead to greater future fan ties; whatever signaling occurred between attending sport events and future friendships, the same did not occur within the fan network. Both the fan and friendship networks 
were marked by reciprocity, consistent with other network studies of directed networks, generally, and friendships specifically (Borgatti et al., 2013; Robins, 2015). Given the presence of reciprocal effects, the meaningfulness and impact of both the fan ties and friendship ties appear largely even on both sides of the relationships. This intuitively makes sense since it takes two people to attend a game together. Yet, a significant reciprocal effect reinforces that 'co-consumption' approach of sport consumer behavior. A growing line of researchers have emphasized how fans co-create value through their interactions (Uhrich, 2014; Woratschek, Horbel, \& Popp, 2014), and the reciprocal nature of fan ties illustrates such co-creation.

The presence of transitivity also suggests a network foundation to co-creation of value among sport spectators. The presence of hierarchical closure (i.e., transitive triplets), rather than generalized reciprocity (i.e., three cycles), illustrates that fan networks are influenced by a localized hierarchy. Put another way, a social hierarchy exists within the transitivity of the fan network suggesting the influence of key nodes or actors in the network. Rather than a generalized reciprocity where ties are evenly distributed, the transitive nature of the network is marked by hierarchical closure where select nodes are largely responsible for connecting various actors (Ripley et al., 2019). Such a finding is consistent with Katz and Heere's (2013) work on network 'leaders' and scale-free networks. Of note, however, is that these network leaders do not necessarily increase their status over time. Being popular in the fan network does not lead to greater incoming ties moving forward, illustrated by the lack of an indegree popularity effect. Network leaders begin as central actors, and over the course of this study the leaders in the fan network largely remained consistent in their hierarchical role.

The lack of significant effects based on team identification as a covariate was a surprising finding, particularly in the fan tie network. Homophily is a fairly standard and often-replicated finding within network studies, as individuals tend to create relationships with actors who are similar to themselves (Prell, 2011). The premise of the covariate effects was based on homophily (i.e., fan ties would occur based on shared similarities of team identification). Surprisingly, this was simply not the case for the 13 participants in this study, as there was no significant support for the similarity effect based on team identification.

Moreover, we were also surprised that team identification as a covariate was not significant at either the ego or alter effect level. Given the popularity of team identification research in sport management (James et al., 2019; Lock \& Heere, 2017), we expected individuals with higher levels of team identification to play a more focal role in the fan tie network, either through creating more outgoing fan ties or eliciting more incoming fan ties. Nevertheless, team identification did not significantly affect incoming ties nor outgoing ties for the participants in this study. It is challenging to explain why non-significant results occurred in our model, but perhaps the 'leaders' of fan networks are not leaders based a heightened identity with the team. In other words, perhaps leadership in fan networks is based on some other individual attribute (i.e., gender, personality traits) beyond team identity. Katz, Baker, and Hui (2020) found a similar result in their study of a soccer supporters club, showing how the 
most passionate (i.e., highly identified) were not the most influential in the network. Based on the results of the current study, we similarly propose that team identity does not inherently equal network influence; sport fan ties or sport fan network centrality is not synonymous with levels of team identity. As sport scholars continue to utilize group marketing frameworks, whether they be network-based or not, the most identified consumers may not play the largest role in influencing the rest of the group.

We also found no evidence for team identification effects for friendship ties, either at the ego, alter, or similarity level. Team identification did not play a role in the development of friendship ties, providing no evidence of homophilous friendship ties based on team identification for the participants in this study. Future scholars might consider what attributes, beyond team identification, impact the creation, continuation, and potential termination of sport fan ties.

\section{Practical Implications}

Beyond the theoretical implications of the current research, there are a number of practical implications based on the results of our longitudinal actor-based network study. First, to maximize the value of Division III athletics on campus, campus leaders could use sport early to assist in the development of new friendships for incoming students. Though attending games together did not significantly predict developing a friendship, those individuals attending with many others were more likely to elicit friendships moving forward. Accordingly, attending sporting events on a Division III campus can be viewed as a cause of social integration; attendance is not merely for the experience of consuming sport but a vehicle to generate popularity in friendship networks. Attendance at Division III sporting events often has few of the traditional barriers of commercialized sport; games are largely free, frequent, and located near student housing. Such ingredients fashion a situation conducive to salubrious socialization, particularly when social spaces are available surrounding the actual sport event. Making attendance ties visible and providing opportunities for new students to leverage fan ties into friendships may be the optimal outcome for sponsoring Division III sports.

Based on average attendance data for most Division III institutions, the spectator experience is far different at South College than "big-time" NCAA institutions. When a student is surrounding by 100,000 others at a University of Texas or Texas A\&M football game, the size of the crowd may be overwhelming and unconducive to affecting friendship ties later in ones' campus integration experience. With smaller crowds, less commercialized activities, and dampened cultural expectations to attend, attendance may signal something to other students who created friendship ties moving forward. The atmosphere at Division III events may characterize an environment more conducive for formulating interpersonal relationships. Incentivizing and encouraging new students to attend sporting events with other new students has value not only for the individual student, but for the institution at large as well.

\section{Limitations and Directions for Future Research}

Though the results of this study are insightful, the specific research setting limits the generalizability of the findings. This represents both the opportunity and challenge 
for studying the role of college sports on campus: every campus is different. Hopefully this study serves as a starting point to better understand not only how college sport impacts the social fabric of campus, but also what characteristics of college athletics maximize (or minimize) that potential impact. Is football important? Does winning matter? In terms of impacting campus, is there a relationship between enrollment and the level of competition needed? Scholars should continue examining not only the theoretical relationship between sport and different institutional outcomes, but also the characteristics of the sporting structure that best elicit positive organizational and individual outcomes.

Additionally, some of the methodological decisions in this study are worth noting as potential limitations. Namely, measuring both friendships and consumption ties through binary yes/no answers may oversimplify the nature of these relationships. Had participants been given a chance to weigh their answers, perhaps indicating the degree of one's friendships or providing the number of events co-attended, that may have provided more variance in the network. Next, the only ties included in this study were friendship and consumption of sport. There are, undoubtedly, many other relationships that underlie the college experience. This study did not measure if students studied together, ate together, went on vacation together or any other type of relationship. Future research may want to include other types of relationships to more appropriately isolate the role of co-consumption ties. And finally, all network studies struggle with identifying network boundaries and population criteria. We utilized a freshman orientation group, but it is impossible to deny the possibility of boundary spanners that were left out of the network. Perhaps there were key players in the friendship network that lived in a different dormitory or were a member of a different orientation group. If boundary spanners are a potential concern, future researchers might consider utilizing an ego network analysis that allows for the inclusion of such actors (Katz, Heere, \& Melton, 2020; Perry, Pescosolido, \& Borgatti, 2018).

\section{Conclusion}

While the bright lights of media attention and consumer interest continue to focus on "big-time" college athletics, some 440 institutions of higher learning continue to compete in Division III intercollegiate athletics. For Division III sponsoring institutions, sports on campus may not yield the same level of national publicity but they may impact key organizational goals such as persistence and retention. With nearly $20 \%$ of students not matriculating past their first year (McFarland et al., 2018) and the average institution losing nearly $\$ 10$ million to student attrition, the value of Division III sports in promoting retention should not be overlooked. Scholars in student development have long emphasized the salience of peer relationships (Astin, 1999) and social integration (Tinto, 1993) in matters of persistence. Based on a two-year actor-based network study of new students, the current research found that attending sporting events on campus influenced the development of friendship ties and social integration. Sport fan ties might not cause friendships; but they are significantly related. Sport management researchers have emphasized the importance of 
fan-to-fan relationships (Katz et al., 2018) and the co-creation of value among sport fans (Uhrich, 2014), and these fan ties affect the evolution of friendship ties as well.

A student's peer relationships are the single best predictor of success in college (Astin, 1999) - and for the participants in this study, the presence of Division III sports on campus assisted in the evolution of incoming friendship ties. Katz et al. (2017) stated that Division III sports represent the front porch of a small house in terms of promoting attitudes toward the larger university for new students. We extend that sentiment, showing that fan ties affect friendships and social integration. Individual attributes are no doubt important to questions surrounding retention and persistence, yet the entirety of the network tradition rests on the assumption that individual attitudes are only part of the story - individual outcomes are affected by social relationships and the resulting structure of those relationships (Robbins, 2015). As the discourse examining college sport and student attitudes continues to develop (Clopton, 2008; Heere \& Katz, 2014; Wann \& Robinson, 2002; Warner et al., 2011) the impact of sports on campus includes more than attitudinal development. The linkage between sports on campus and institutional outcomes includes the formation and maintenance of meaningful interpersonal relationships.

\section{References}

Allison, P. (2002). Quantitative applications in the social sciences: Missing data. Thousand Oaks, CA: SAGE.

Asada, A., \& Ko, Y. J. (2019). Conceptualizing relative size and entitativity of sports fan community and their role in sport socialization. Journal of Sport Management, 33, 530-545.

Astin, A. (1999). Student involvement: A developmental theory for higher education. Journal of College Student Development, 40(5), 518-529.

Balkundi, P., \& Kilduff, M. (2006). The ties that lead: A social network approach to leadership. The Leadership Quarterly, 17, 419-439.

Borgatti, S. P., \& Foster, P. C. (2003). The network paradigm in organizational research: A review and typology. Journal of Management, 29, 991-1013.

Borgatti, S. P., \& Halgin, D. (2011). On network theory. Organization Science, 22, 1168-1181.

Borgatti, S. P., Everett, M. G., \& Johnson, J. C. (2013). Analyzing social networks. Thousand Oaks, CA: SAGE.

Brass, D. J., Labianca, G., Mehra, A., Halgin, D. S., \& Borgatti, S. P. (2014). Contemporary perspectives on organizational social networks. Bingley, UK: Emerald Group Publishing.

Chalip, L. (2006). Toward a distinctive sport management discipline. Journal of Sport Management, 20, 1-21.

Clopton, A. W. (2008). College sports on campus: Uncovering the link between fan identification and sense of community. International Journal of Sport Management, 9, 1-20. 
Clopton, A. W., \& Finch, B. L. (2008). Are college students 'Bowling Alone?' Examining the contribution of team identification to the social capital of college students. Journal of Sport Behavior, 33, 377-402.

Guttman, A. (1986). Sports spectators. New York, NY: Columbia University Press.

Heere, B., \& James, J. D. (2007). Stepping outside the lines: Developing a multi-dimensional team identity scale based on social identity theory. Sport Management Review, 10, 65-91.

Heere, B., \& Katz, M. (2014). Still undefeated: Exploring the dimensions of team identity among fans of a new college football team. Journal of Applied Sport Management, 6, 25-42.

Inoue, Y., Sato, M., Filo, K., Du, J., \& Funk, D.C. (2017). Sport spectatorship and life satisfaction: A multi-country investigation. Journal of Sport Management, $31,419-432$.

InsideTrack. (2018, September 18). Understanding the reasons behind leaving school: How Inside Track turns would-be dropouts into college graduates. https://www.insidetrack.com/resources/understanding-the-reasons-behindleaving-school-how-insidetrack-turns-would-be-dropouts-into-college-graduates/

James, J. (2001). The role of cognitive development and socialization in the initial development of team loyalty. Leisure Sciences, 23, 233-261.

James, J. D., Delia, E. B., \& Wann, D. L. (2019). "No" is not "Low": Improving the Assessment of Sport Team Identification. Sport Marketing Quarterly, 28, 34-45.

Johnson, D.R., Soldner, M., Leonard, J.B., Alvarez, P., Inkelas, K.K., Rowan-Kenyon, H., \& Longerbeam, S. (2007). Examining sense of belonging among firstyear undergraduates from different racial/ethnic groups. Journal of College Student Development, 48(5), 525-542.

Katz, M., \& Clopton, A. W. (2014). Town \& gown...\& jerseys? NCAA Division III athletics as social anchors. Journal of Issues in Intercollegiate Athletics, 7 , 285-306.

Katz, M., Baker, T. A., \& Du, H. (2020). Team identity, supporter club identity, and fan relationships: A brand community network analysis of a soccer supporters club. Journal of Sport Management, 34, 9-21.

Katz, M., Dixon, M. A., Heere, B., \& Bass, J. R. (2017). Front porch, small house: A longitudinal study of team and university identification among incoming students at a Division III university. Journal of Intercollegiate Sport, 10, 103-125.

Katz, M., \& Heere, B. (2013). Leaders and followers: An exploration of the notion of scale-free networks within a new brand community. Journal of Sport Management, 27, 271-287.

Katz, M., \& Heere, B. (2016). New team, new fans: A longitudinal examination of team identification as a driver of university identification. Journal of Sport Management, 30, 135-148.

Katz, M., Heere, B., \& Melton, E. N. (2020). Predicting fan behavior through egocentric network analysis: Examining season-ticket holder renewal. Journal of Sport Management, 34, 217-228. 
Katz, M., Ward, R. M., \& Heere, B. (2018). Explaining attendance through the brand community triad: Integrating network theory and team identification. Sport Management Review, 21, 176-188.

Lock, D., \& Funk, D. C. (2016). The multiple in-group identity framework. Sport Management Review, 19, 85-96.

Lock, D., \& Heere, B. (2017). Identity crisis: A theoretical analysis of 'team identification' research. European Sport Management Quarterly, 4, 413-435.

Lock, D., Taylor, T., Funk, D., \& Darcy, S. (2012). m the development of team identification. Journal of Sport Management, 26, 283-294.

Marin, A., \& Wellman, B. (2014). Social network analysis: An introduction. In J. Scott \& P. J. Carrington (Eds). The SAGE handbook of social network analysis (pp. 11-25). Thousand Oaks, CA: SAGE.

Maunder, R. E. (2018). Students' peer relationships and their contribution to university adjustment: The need to belong in the university community. Journal of Further and Higher Education, 42(6), 756-768.

McEwan, B. (2013). Retention and resources: An exploration of how social network resources relate to university commitment. Journal of College Student Retention, 15, 113-128.

McFarland, J., Hussar, B., Wang, X., Zhang, J., Wang, K., Rathbun, A., Bramer, A., Cataldi, E. F., \& Mann, F. B. (2018). The condition of education 2018. NCES 2018-144. National Center for Education Statistics.

McKnight, P. E., McKnight, K. M., Sidani, S., \& Figueredo, A. J. (2007). Missing data: A gentle introduction. New York, NY: Guilford Press

Pascarella, E. T. \& Terenzini, P. T. (2005). How college affects students. San Francisco, CA: Josey-Bass.

Perry, B. L., Pescosolido, B. A., \& Borgatti, S. P. (2018). Egocentric network analysis: Foundations, methods, and models. Cambridge, UK: Cambridge University Press.

Prell, C. (2012). Social network analysis. Thousand Oaks, CA: SAGE.

Quatman, C., \& Chelladurai, P. (2008). Social network theory and analysis: A complementary lens for inquiry. Journal of Sport Management, 22, 338-360.

Raisman, N. A. (2013). The cost of college attrition at four-year colleges \& universities. Educational Policy Institute Policy Perspectives.

Ripley, R. M., Snijders, T. A. B., Boda, Z., Voros, A., \& Preciado, P (2019). Manual for SIENA version 4.0. Oxford: University of Oxford Press.

Robins, G. (2015). Doing social network research. Thousand Oaks, CA: SAGE.

Rubin, D. B. (2004). Multiple imputation for nonresponse in surveys (Vol. 81). Hoboken, NJ: Wiley \& Sons

Schafer, J. L., \& Graham, J. W. (2002). Missing data: Our view of the state of the art. Psychological Methods, 7, 147-177.

Schneider, M. (2010). Finishing the first lap: The cost of first-year student attrition in America's four-year colleges and universities. American Institute for Research.

Snijders, T. A. B., van den Bunt, G. G., \& Steglich, C. E. G. (2010). Introduction to actor-based models for network dynamics. Social Networks, 32, 44-60. 
Snijders, T. A. B., Lomi, A., \& Torlo, V., J. (2013). A model for the multiplex dynamics of two-mode and one-mode networks with an application to employment preference, friendship, and advice. Social Networks, 35, 265-276.

Stensland, P. J., Taniyev, O., Scola, Z., Ishaw, F. J., Wilkerson, Z., \& Gordon, B. S. (2019). The ties that bind: Examining Division I athletics as a social anchor. Journal of Issues in Intercollegiate Athletics, 12, 287-313.

Strayhorn, T.L. (2012). College students' sense of belonging: A key to educational success for all students. New York: Routledge.

Strom, R.E., \& Savage, M.W. (2014). Assessing the relationships between perceived support from close others, goal commitment, and persistence decisions at the college level. Journal of College Student Development, 55(5), 531-547.

Swenson, L. M., Nordstrom, A., \& Hiester, M. (2008). The role of peer relationships in adjustment to college. Journal of College Student Development, 49(6), 551567.

Tajfel, H. (1982). Social psychology of intergroup relations. Annual Review of Psychology, 33, 1-39.

Thomas, S.L. (2000). Ties that bind: A social network approach to understanding student integration and persistence. The Journal of Higher Education, 71(5), 591-615.

Tinto, V. (1975). Dropout from higher education: A theoretical synthesis of recent research. Review of Educational Research, 45, 89-125.

Tinto, V. (1993). Leaving college: Rethinking the causes and cures of student attrition ( $2^{\text {nd }}$ Edition). Chicago, IL: University of Chicago Press.

Tinto, V. (2006). Research and practice of student retention: What next? Journal of College Student Retention: Research, Theory \& Practice, 8, 1-19.

Uhrich, S. (2014). Exploring customer-to-customer value co-creation platforms and practices in team sports. European Sport Management Quarterly, 14, 25-49.

Valente, T. W. (2010). Social networks and health: Models, methods, and applications. Oxford: Oxford University Press.

Wann, D. L., \& Robinson T. N., III. (2002). The relationship between sport fan identification and integration into and perceptions of a university. International Sports Journal, 6, 36-44.

Warner, S., Shapiro, S. L., Dixon, M. A., Ridinger, L. L., \& Harrison, S. B. (2011). The football factor: Shaping community on campus. Journal of Issues in Intercollegiate Athletics, 4, 236-256.

Webber, K. L., Krylow, R. B., \& Zhang, Q. (2014). Does involvement really matter? Indicators of college student success and satisfaction. Journal of College Student Development, 54, 591-611.

Woratschek, H., Horbel, C., \& Popp, B. (2014). The sport value framework-a new fundamental logic for analyses in sport management. European Sport Management Quarterly, 14(1), 6-24.

Yoshida, M., Heere, B., \& Gordon, B. (2015). Predicting behavioral loyalty through community: Why other fans are more important than our own intentions, our satisfaction, and the team itself. Journal of Sport Management, 29, 318-333. 